\title{
Second-generation thermal endometrial ablation: beware of metal clips in the lower abdomen
}

\author{
J. W. van den Brink • Kirsten Kluivers • \\ Theodoor Nieboer
}

Received: 17 December 2012 / Accepted: 16 January 2013 /Published online: 7 February 2013

(C) Springer-Verlag Berlin Heidelberg 2013

\section{Introduction}

In The Netherlands, the incidence of excessive vaginal blood loss in fertile women is 5.2 per 1,000 women (National Guideline of GPs, 2008). Endometrial ablation is a widely used treatment for patients with abnormal or excessive vaginal blood loss because of it is efficacy and safety [1]. Complications during or after endometrial ablation are rare, and hysterectomy can be avoided [2, 3].

The first-generation endometrial ablation techniques were introduced in the mid-1980s and included loop resection, rollerball, or laser ablation [1]. These techniques require visualization of the uterine cavity [4]. Several complications may occur such as fluid overload syndrome, uterine perforation, cervical laceration, or hematometra. New techniques have been developed since 1990; these are known as the second-generation ablation techniques, and hysteroscopy is not necessary in the majority of these techniques $[4,5]$. The second-generation ablation techniques include thermal balloon (ThermaChoice), hot fluid circulation (Hydro ThermAblator), cryotherapy (Her Option), microwave energy (MEA), and radiofrequency electrosurgery (NovaSure) [1]. In a Cochrane database metaanalysis, these new techniques were associated with shorter operative time (median difference, $15 \mathrm{~min}$ ), a greater likelihood for the use of local anesthesia and less complications compared to the first-generation techniques [6]. Therefore, the second-generation endometrial ablation techniques are currently widely used.

The NovaSure consists of a single-use three-dimensional bipolar device and a radiofrequency controller with a constant

J. W. van den Brink $(\bowtie) \cdot$ K. Kluivers $\cdot$ T. Nieboer

Radboud University Nijmegen Medical Centre-Obstetrics/

Gynaecology, Nijmegen, The Netherlands

e-mail: J-W.vandenbrink@obgyn.umcn.nl power generator (maximum power delivery capacity, $180 \mathrm{~W}$ ). It functions at $500 \mathrm{kHz}$ with a power cut-off limit at a tissue impedance of $50 \Omega$. To prevent heating of the extra-uterine environment, tissue impedance is monitored continuously. In general, the endometrial layer has a tissue impedance $<50 \Omega$ and the myometrial layer $\geq 50 \Omega$, and the generator will switch off automatically when the myometrial layer is reached or after a maximum procedure time of $2 \mathrm{~min}$ [7]. Due to the controller, the NovaSure is considered as a relatively safe endometrial ablation technique.

We report a case in which persistent abdominal pain occurred after endometrial ablation with the NovaSure, most likely due to heat conductance through tubo-isthmic-placed metal hemoclips.

\section{Case report}

A 45-year-old multiparous woman visited the outpatient clinic with hypermenorrhoea which resulted in hypochromic anemia. For 2 years, she suffered hypermenorrhoea responding neither to oral contraceptive pills nor to a levonorgestrel intrauterine device. Her medical history included a laparoscopic right-sided salphingectomy due to an ectopic pregnancy.

Transvaginal ultrasound showed a subserosal myoma of $2.7 \times 1.7 \mathrm{~cm}$ in a moreover normal-size uterus; no adnexal abnormalities were seen. After counseling for all therapeutic options, a NovaSure procedure was planned under general anesthesia. A preoperative checklist was executed, and no contraindications for the NovaSure were found. Hysteroscopy prior to the NovaSure procedure, which is a local hospital policy in our center, showed a normal uterine cavity. The sounding length was $10 \mathrm{~cm}$ with a cavity width of $2.8 \mathrm{~cm}$, and the power was $100 \mathrm{~W}$, the procedure time was $64 \mathrm{~s}$. Hysteroscopy directly after the 
procedure showed a fully disintegrated endometrium without signs of uterine perforation.

Two days after endometrial ablation, the patient complained of lower abdominal pain with a body temperature of $38.1{ }^{\circ} \mathrm{C}$. Laboratory test showed elevated infection parameters: C-reactive protein $251 \mathrm{mg} / \mathrm{L}$ (normal range, $<10 \mathrm{mg} / \mathrm{L}$ ) and leucocytes $16.4 \times 10^{9}$ per liter (normal range, $4-11 \times 10^{9}$ per liter). Cultures were taken from the cervix, and broad-spectrum antibiotics were administered intravenously. After 3 days, the patient's clinical condition enhanced, and infection parameters dropped significantly, and she was discharged from hospital. Oral antibiotics were continued for 2 weeks. Culture of the cervix showed a group B streptococcus.

During follow-up in the outpatient clinic, she kept complaining of right-sided abdominal pain despite the use of multiple analgesics and antibiotics. Abdominal examination revealed a pressure pain in the lower right abdomen without rebound tenderness. Laboratory tests showed C-reactive protein $5 \mathrm{mg} / \mathrm{L}$ and leucocytes $8.8 \times 10^{9}$ per liter. Transvaginal ultrasound showed no abnormalities. Due to the persistence of pain 5 weeks after surgery, a CT scan was performed. This showed an unexpected finding of multiple metal clips on the right side of the uterus and one clip near the umbilicus. There were no signs of tubo-ovarian abscesses. On further inquiry, it was obvious that these clips were metal hemoclips placed during removal of the right fallopian tube due to an ectopic pregnancy 18 years ago in another medical center. We hypothesized that heat conductance during the endometrial ablation through the metal hemoclips might have led to thermal damage of the uterine cornu and parametrium. A diagnostic hysteroscopy and laparoscopy was performed. At hysteroscopy, there was a normal uterine cavity, and some regeneration of the endometrial layer was seen. During laparoscopy, normal ovaries were seen. Two right-sided tubo-isthmic-placed metal hemoclips were located with erythema of the cornu as a sign of inflammation (Fig. 1). Furthermore, four metal hemoclips were located on the lateral side of the parametrium without signs of inflammation (Fig. 2). No signs of abscesses were seen. The two tubo-isthmic-placed metal hemoclips were removed and the cornu was coagulated, while the other metal hemoclips remained in situ.

Within 3 weeks after surgery, the patient's abdominal pain decreased, and she recovered completely. The removed endometrium showed on pathological examination no signs of hyperplasia or atypia.

\section{Discussion}

We report a case in which a rare complication occurred after endometrial ablation, presumably due to heat conductance

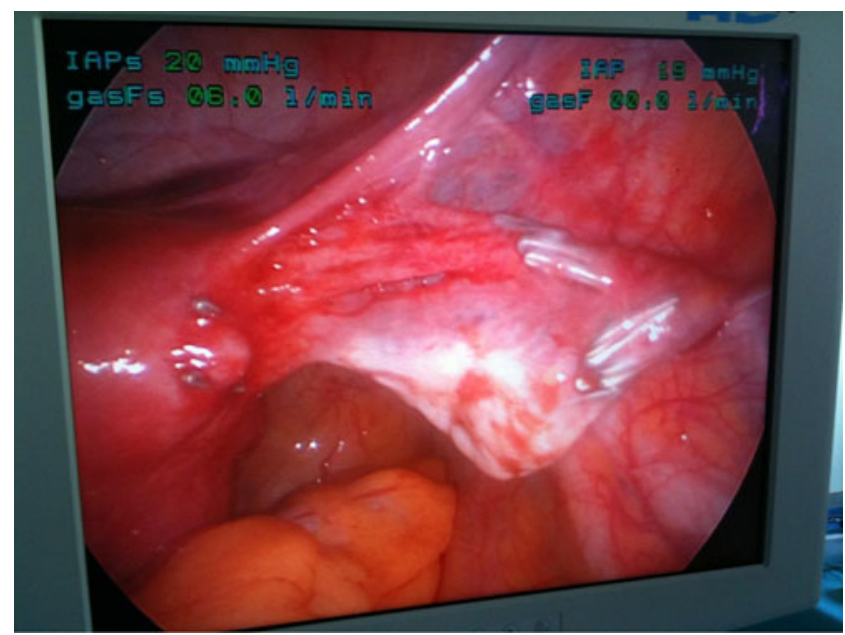

Fig. 1 Laparoscopic view of the right ovary, uterine cornu, and round ligament. At least seven hemoclips are visible

through tubo-isthmic-placed metal hemoclips. We hypothesize that the abdominal pain was caused by thermal damage because after antibiotic treatment, she kept complaining of abdominal pain despite normal infection parameters. In cases of persistent abdominal pain after endometrial ablation of unknown origin, further diagnostic evaluation is advocated. In our case, a CT scan was performed because no abnormalities were found after transvaginal ultrasound. The metal hemoclips had not been visible on transvaginal ultrasound, although the metal hemoclips might theoretically have been detectable with a transvaginal ultrasound as well.

The instructions for use the NovaSure include a list of contraindications (http://www.novasure.com/pdf/info/ Instructions.pdf). "Patients with potential thermally conductive object in the uterus or in the uterine cavity should be

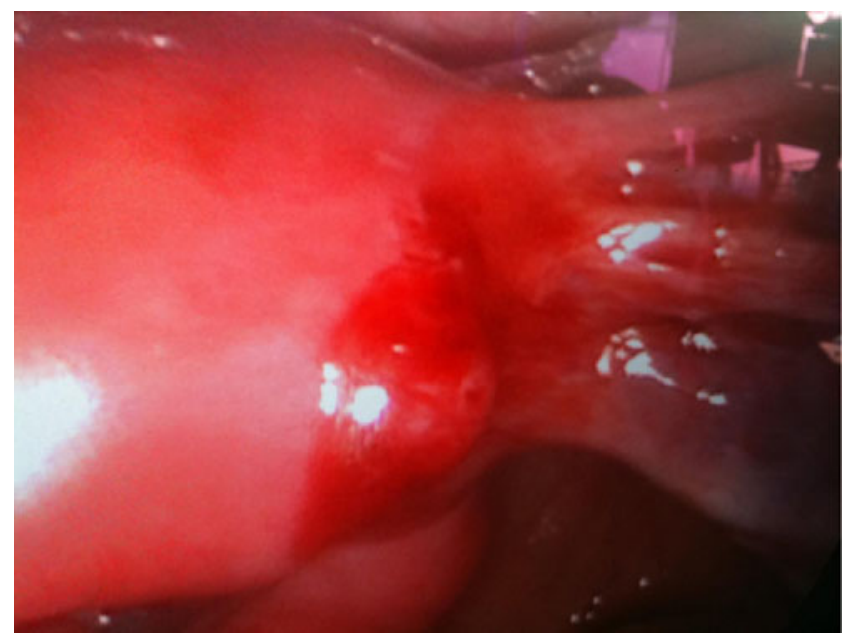

Fig. 2 Zoomed laparoscopic view of the right uterine cornu after resection of two hemoclips. Clearly visible is the enhanced erythema on the spot where the hemoclips were located 
excluded for the NovaSure procedure because the presence of a conductive object may be sufficient to cause localized burns." Our case demonstrates that even a tubo-isthmicplaced metal hemoclip can cause localized thermal damage. From an anatomical point of view, this may be explained by the fact that the cornua have less myometrial thickness. Regarding the complications after second-generation endometrial ablation, several studies have been reported $[8,9]$. Table 1 shows the reported complications in literature after second-generation endometrial ablation.

With regard to thermic complications after endometrial ablation, Iliodromiti et al [10]. reported a major thermic complication after MEA. A 41-year-old woman underwent a MEA because of menorrhagia. She had a history of laparoscopic sterilization without signs of adhesions in the pelvis. The day after the MEA, she presented with clinical signs of acute abdomen. A laparotomy was performed, and multiple bowel perforations were seen, as well as a retroflected uterus with an anterior wall perforation and evident thermal damage of the serosal and uterovesical peritoneum and distal ileum. A right hemicolectomy with extended ileal resection and a subtotal hysterectomy was performed. The postoperative recovery was complicated by pneumonia and wound infection. After 19 days, she was discharged from hospital.

In our hospital, we had a bowel injury after the NovaSure procedure through a perforated uterus. Another case of bowel injury after the NovaSure is known from another Dutch center (unpublished data). The number of complications available in literature seems too low due to underreporting. Therefore, a national system for registration of complications is desirable. Currently, such a system is being implemented in The Netherlands.

An infection may occur as a rare short-term complication after endometrial ablation and serious infectious complications have been described in three case reports [11-13]. Das et al [11]. reported a case of a patient with a history of endometriosis. She received a MEA because of menorrhagia. Due to persisted menorrhagia 3 years later, a second MEA was performed. On re-admission because of abdominal pain, the patient had elevated infection parameters, and ultrasound showed a pelvic mass of $6 \mathrm{~cm}$. Therefore, a laparotomy was planned and showed a pelvic abscess of $7 \times 10 \mathrm{~cm}$, adhesions, and an ovarian endometrioma. Jansen et al [12]. have described a case of bilateral cornual abscess after NovaSure 1 year after Essure sterilization. Symptoms of abdominal pain and fever started shortly after endometrial ablation. Ultrasound showed a mass of $5 \mathrm{~cm}$ in the right iliac fossa with elevated levels of C-reactive protein and leucocytes. A tuboovarian abscess was suspected, and after antibiotics were administered, a laparoscopy was performed. Due to extensive adhesions, a conversion to laparotomy was done, and after adhesiolysis, both cornua of the uterus showed abscesses and necrosis. After removing the abscesses, necrosis, fallopian

Table 1 Case reports of complications after second-generation endometrial ablation

\begin{tabular}{|c|c|c|c|c|}
\hline Authors (year) & Type of ablation & Medical history & Complication & Intervention \\
\hline Hubert $2001[14]$ & HTA & Cervical incompetence & $\begin{array}{l}\text { Hematometra after cervical } \\
\text { occlusion }\end{array}$ & Cervical dilatation and stent \\
\hline Roth 2004 [15] & ThermaChoice & $2 \mathrm{CS}$ & $\begin{array}{l}\text { Bilateral tubo-ovarian } \\
\text { abscesses } 50 \text { days later }\end{array}$ & $\begin{array}{l}\text { Abdominal hysterectomy and } \\
\text { bilateral salpingo-oophorectomy }\end{array}$ \\
\hline Das 2005 [11] & $\begin{array}{c}\text { 2nd MEA } 3 \text { years } \\
\text { after first MEA }\end{array}$ & $\begin{array}{l}\text { Twin pregnancy after IVF, CS, } \\
\text { MEA, endometriosis }\end{array}$ & $\begin{array}{l}\text { Pelvic abscess } 7 \times 10 \mathrm{~cm} \text { with } \\
\text { ovarian endometrioma }\end{array}$ & $\begin{array}{l}\text { Hysterectomy and bilateral } \\
\text { salpingo-oophorectomy }\end{array}$ \\
\hline Gandhi 2005 [16] & Cavatherm & Unknown & Ectopic pregnancy & Unknown \\
\hline Janssen 2007 [12] & NovaSure & Essure sterilization & Bilateral cornual abscess & $\begin{array}{l}\text { Laparotomy, resection of necrosis, } \\
\text { removing of Essure microinserts }\end{array}$ \\
\hline Robson 2007 [17] & HTA & Resection of leiomyoma type 0 & Necrotic leiomyoma & Hysteroscopy \\
\hline Robson 2007 [17] & HTA & 3 intramural Leiomyoma & Necrosis of leiomyoma & $\begin{array}{l}\text { Conservative therapy with } \\
\text { antibiotics }\end{array}$ \\
\hline Schlumbrecht 2007 [18] & HTA & $\begin{array}{l}\text { Diabetes type } 2 \text { Prosthetic } \\
\text { mitral valve }\end{array}$ & $\begin{array}{l}\text { Pyometra and sepsis } \\
\text { Cervical necrosis }\end{array}$ & Hysterectomy \\
\hline V. Riemsdijk 2009 [5] & NovaSure & Myoma (4 cm) & Expulsion of myoma & Hysterectomy \\
\hline Salmeen 2009 [13] & NovaSure & - & $\begin{array}{l}\text { Sepsis within } 36 \mathrm{~h} \\
\quad(\text { Escherichia coli) }\end{array}$ & $\begin{array}{l}\text { Exploratory laparotomy and } \\
\text { hysterectomy }\end{array}$ \\
\hline Rooney 2010 [19] & NovaSure & $3 \mathrm{CS}$ & $\begin{array}{l}\text { Vesico-uterine fistula } 2 \text { weeks } \\
\text { after NovaSure }\end{array}$ & $\begin{array}{l}\text { supracervical laparoscopic } \\
\text { hysterectomy repair of fistula }\end{array}$ \\
\hline Iliodromiti 2011 [10] & MEA & Laparoscopic sterilization & $\begin{array}{l}\text { Thermal bowel injuries } \\
\text { with perforations }\end{array}$ & $\begin{array}{l}\text { Exploratory laparotomy } \\
\text { with subtotal hysterectomy, } \\
\text { hemicolectomy }\end{array}$ \\
\hline
\end{tabular}

MEA microwave endometrial ablation, HTA hydrothermal ablation, $C S$ caesarean section 
tubes, and Essure microinserts, the patient's postoperative recovery was quick and uneventful. Salmeen et al [13]. reported a sepsis $36 \mathrm{~h}$ after a NovaSure procedure. Intravenous antibiotics, fluid resuscitation, and an exploratory laparotomy with hysterectomy were performed. The patient recovered quickly after hysterectomy. Blood cultures and uterine tissue grew Escherichia coli.

Pregnancy after endometrial ablation has been described in literature in approximately 60 cases. Some pregnancies may have been counted twice due to double reports in case reports, case series, and reviews. In summary, major complications such as placenta accreta or increta, uterine rupture, massive blood loss, fetal malformations, miscarriage, and stillborn have been reported. Therefore, physicians should counsel their patients accurately to use complementary contraceptive methods.

\section{Conclusion}

In conclusion, endometrial ablation is a widely used method to treat excessive vaginal blood loss, and it is generally a safe and effective procedure. However, rare but serious complications may occur. Patients with a history of pelvic surgery with metal clips in the abdomen or pelvis should be counseled for complications such as thermal damage of extra-uterine tissue. It is preferable in these patients to remove these metal hemoclips prior to endometrial ablation or choose a non-surgical treatment for excessive vaginal bleeding.

Conflict of interest The authors report no conflicts of interest. The authors alone are responsible for the content and writing of the paper.

\section{References}

1. Sharp HT (2006) Assessment of new technology in the treatment of idiopathic menorrhagia and uterine leiomyomata. Obstet Gynecol 108:990-1003
2. Abbott JA, Garry R (2002) The surgical management of menorrhagia. Hum Reprod Update 8(1):68-78

3. Kleijn J, Engels R, Bourdrez P, Mol B, Bongers M (2008) Fiveyear follow up of a randomized controlled trial comparing NovaSure and ThermaChoice endometrial ablation. BJOG 115:193-198

4. Lethaby A, Hickey M, Garry R (2009) Endometrial resection/ ablation techniques for heavy menstrual bleeding. Cochrane Database of Systematic Reviews Issue 4. Art. No.: CD001501. doi:10.1002/14651858.CD001501.pub3

5. Van Riemsdijk VMJ, Graziosi GCM, Veersema S, Bongers MY (2009) Vaginal myoma expulsion after NovaSure endometrial ablation. J Minim Invasive Gynecol 16:496-497

6. Lethaby A, Hickey M, Garry R (2005) Endometrial destruction techniques for heavy menstrual bleeding (Cochrane Review). In: The Cochrane Library, Issue 4, Oxford: Update Software

7. Bongers MY (2007) Second-generation endometrial ablation treatment: NovaSure. Best Pract Res Clin Obstet Gynaecol 21(6):989994

8. Della Badia C, Nyirjesy P, Atogho A (2007) Endometrial ablation devices: review of a manufacturer and user facility device experience database. J Minim Invasive Gynecol 14(4):436-441

9. Campbell P, Monaghan C, Parker M (2012) NovaSure endometrial ablation: a review of 400 cases. Gynaecol Surg 9:73-76

10. Iliodromiti S, Murage A (2011) Multiple bowel perforations requiring extensive bowel resection and hysterectomy after microwave endometrial ablation. J Minim Invasive Gynecol 18:118-120

11. Das S, Krwan J, Drakely AJ, Kingsland CR (2005) Pelvic abscess following microwave endometrial ablation. BJOG 112:118-119

12. Jansen NE, Vleugels MPH, Kluivers KB, Vierhout ME (2007) Bilateral cornual abscess after endometrial ablation following Essure sterilization. J Minim Invasive Gynecol 14:509-511

13. Salmeen K, Morgan D (2009) Sepsis after bipolar radiofrequency endometrial ablation. Obstet Gynecol 114(2):445-448

14. Hubert SR, Marcus PS, Rothenberg JM, Schilder JM, Hurd WW (2001) Hematometra after thermal balloon endometrial ablation in a patient with cervical incompetence. J laparoendosc Adv Surg Tech A 11(5):311-313

15. Roth TM, Rivlin ME (2004) Tuboovarian abscess: a postoperative complication of endometrial ablation. Obstet Gynecol 104(5.2):1198 1199

16. Gandhi SV, Habiba MA (2005) Ectopic pregnancy presenting as haematometra following cavaterm balloon endometrial ablation. J Obstet Gynaecol 25(6):614-615

17. Robson S, Devine B (2007) Two cases of leiomyoma necrosis after thermal balloon endometrial ablation. J Minim Invasive Gynecol 14:250-252

18. Schlumbrecht M, Balgobin S, Word L (2007) Pyometra after thermal endometrial ablation. Obstet Gynecol 110:538-540

19. Rooney KE, Cholhan HJ (2010) Vesico-uterine fistula after endometrial ablation in a woman with prior cesarean deliveries. Obstet Gynecol 115:450-451 